\title{
Post partum depression - a problem that needs urgent attention
}

\author{
Ceylon Medical Journal 2011; 56: 183-184
}

Post partum depression (PPD) is a serious mental health condition that has severe acute and chronic effects on mothers, infants, their families and society. In contrary to general reported prevalence of $10-20 \%$ in western countries, PPD has been shown to affect up to $60 \%$ of mothers in some communities [1]. Despite having valid tools for screening, PPD is often under diagnosed, especially in developing countries [2]. In Sri Lanka, a national estimate for PPD is not available. However, Edinburgh Postnatal Depression Scale (EPDS), which is the most widely accepted tool for screening of PPD was validated and used in a large scale study in Puttalam district in 2004. According to this study, the prevalence of postpartum depression was $32.1 \%$ in Puttalam [3]. The purpose of the present study was to estimate the national prevalence of PPD in Sri Lanka.

A descriptive cross sectional study was conducted among mothers of infants ageing 2 weeks to 12 months. The study was conducted in 166 clusters in 18 districts of Sri Lanka, representing eight provinces. The clusters included well baby clinics/immunisation clinics/ paediatric wards or adjacent households. Convenient sampling of clusters was carried out by medical undergraduates as a part of research training. The validated version of EPDS was used in this study with few additional questions on socio-demographic profile of the participants. Cut off points for PPD was taken as 10. Descriptive analysis of data and non parametric statistics were used in the analysis. The study was approved by the Ethical Review Committee of Faculty of Medicine and Allied Sciences, Rajarata University of Sri Lanka.

A total of 1492 postpartum mothers participated in the study. Mean age of the mothers was 28.4 years (SD 5.1years). Prevalence of PPD among the study sample was $27.1 \%$ ( $n=404,95 \%$ CI $24.9 \%-29.4 \%$ ). Thought of self harm (question number 10 of EPDS) was reported (often or sometimes) by $2.9 \%(n=48)$ of the study participants. Primiparous mothers $(191 / 623,30.7 \%)$ and mothers with more than 3 pregnancies $(31 / 75,41.3 \%)$ reported higher level of PPD compared to mothers with two $(126 / 529,23.1 \%)$ or three $(56 / 265,21.8 \%)$ pregnancies (chi-square 19.35, $\mathrm{p}<.001$ ). Prevalence of PPD according to the income quartile (from poorest to richest) was $32.6 \%, 30.6 \%, 23.5 \%$ and $22.4 \%$ respectively (Chi-square 13.77).

The non-probability sampling technique of this study does not allow generalisation of the results. Nevertheless, the large sample size provides sufficient data to show evidence of higher prevalence of PPD in Sri Lanka, which needs urgent attention. 


\section{References}

1. Halbreich U, Karkun S. Cross-cultural and social diversity of prevalence of postpartum depression and depressive symptoms. Journal of Affective Disorders 2006; 91: 97 111.

2. Nielsen FD, Videbech P, Hedegaard M, Dalby SJ, Secher
NJ. Postpartum depression: identification of women at risk. British Journal of Obstetrics and Gynaecology 2000; 107: 1210-7.

3. Rowel DDS. Prevalence, incidence and correlates of postpartum depression in the Puttalam district. Colombo: Post Graduate Institute of Medcine, University of Colombo; 2004.

\section{T C Agampodi ${ }^{1}$, S B Agampodi ${ }^{1}$, W A N D Wickramasinghe ${ }^{1}$, A M C W B Adhikari ${ }^{1}$, H K J U Chathurani $^{1}$}

Department of Community Medicine, Faculty of Medicine and Allied Sciences, Saliyapura

Correspondence: WANDW, e-mail: <nuwick74@yahoo.com>. Received 28 March and accepted 28 May 2011. Competing interests: none declared. 